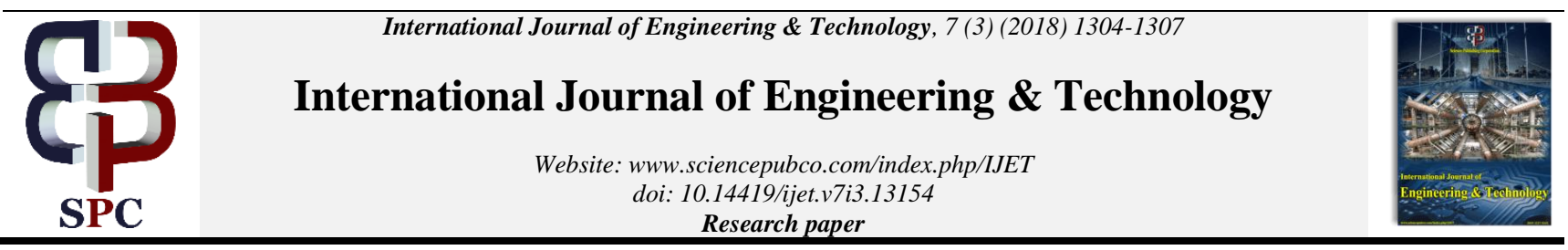

\title{
Wide band multi stage eight way Wilkinson power divider for defense applications
}

\author{
M. Siva Charan ${ }^{1}$ *, A. Rajasekhar ${ }^{1}$ *, K. V. Venkateswara Rao ${ }^{1}$, Ch. Lakshmi Prasanna ${ }^{1}$, Praveen Vummadisetty. \\ Naidu ${ }^{1}$, Gaurav Bansod ${ }^{3}$, Arvind Kumar ${ }^{2}$ \\ ${ }^{1}$ Velagapudi Ramakrishna Siddhartha Engineering College, Vijayawada, India-520007 \\ ${ }^{2}$ K.I.T.E, Jaipur, India-302022 \\ ${ }^{3}$ PICT, Pune, India-411043 \\ *Corresponding author E-mail: rajaalladi.com@gmail.com
}

\begin{abstract}
In this paper, a compact 8 way microstrip line Wilkinson Power Divider (WPD) is designed and proposed. The equal power divider consists of multiple multi-section WPD's with isolation resistors. By utilizing the multi-sections concept, a remarkably increase in the bandwidth is observed. In the design process, RT 5880 substrate is used with the thickness of $0.8 \mathrm{~mm}$ and dielectric constant of 2.2 and loss tangent of 0.0004 . The simulated results such as return loss, insertion loss and isolation are plotted by using ADS simulation software and obtained results show good agreement.
\end{abstract}

Keywords: ADS; Microstrip Line; Multi-Section Wilkinson; N-Way; Wilkinson Power Divider (WPD).

\section{Introduction}

The modern communication system widely uses multiband/wideband antennas [7-21], [26-45], the phased array antennas [22-25] for various commercial and defense applications. Wilkinson power divider plays a vital role in phased array antennas such as power splitting among the antenna array elements with equal amplitude and phase [1]. When the system impedance is matched with ports then reelection co-efficient is zero and maximum power can be delivered. Therefore, the Wilkinson divider is the best choice when compare to T- junction in antenna array [1]. The Wilkinson power divider provides the larger isolation between the output ports so the mutual coupling between the antenna arrays can be reduced.

In 1960, Wilkinson [1] proposed an $\mathrm{N}$-way power divider which split the input signal into ' $N$ ' number of equal phase and amplitude. The standard Wilkinson power divider design has problem at beyond X-band [2]. When the operating frequency increases, the size of the power divider decreases due to the mutual coupling between the output ports [3]. The coupling between the ports causes the power-split ratio and often it is difficult to design the power divider bend semi-circle at higher frequencies [2]. To overcome this problem, in this paper a $3 \lambda / 4$ length of branch line is used in design process instead of $\lambda / 4$. In [4] multiple sections are used to increase the bandwidth. In [5] multiple frequencies are obtained by replacing the quarter wave branches with multiple sections.

In this paper, Multi-sections of two way port cascaded Wilkinson power divider with equal power splitting is designed on the RT 5880 substrate. The simulated return loss and isolation are obtained from $6 \mathrm{GHz}$ to $18 \mathrm{GHz}$ with $-10 \mathrm{~dB}$ and $-15 \mathrm{~dB}$ values respectively.

\section{Power divider design and analysis}

The conventional Wilkinson power divider is shown in Fig.1 consists of a two quarter-wave $(\lambda / 4)$ transformer with terminating impedance $Z_{0}$. The conventional Wilkinson power divider is symmetrical along the mid-line. The basic equal-split Wilkinson power divider has two number of $\sqrt{2} Z_{0}$ transform impedance ( $Z_{0}$ is total system impedance). Impedance calculations and isolation resistor values for equal split WPD is shown in below equations (1)-(6).

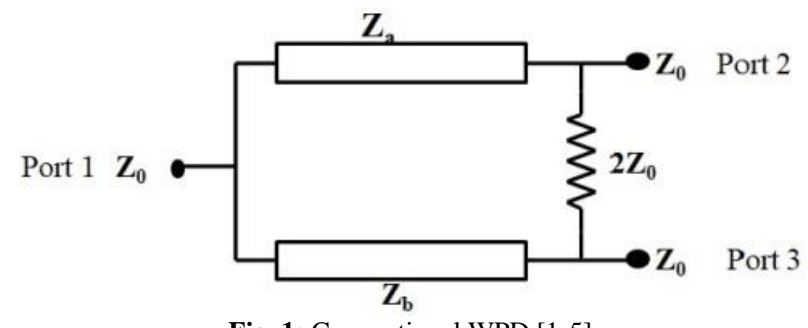

Fig. 1: Conventional WPD [1-5].

$\mathrm{K}^{2}=\frac{\mathrm{P}_{3}}{\mathrm{P}_{4}}$

$\mathrm{K}^{2}=1$ (For equal power split $\mathrm{P}_{2}=\mathrm{P}_{3}=1$ )

$\mathrm{Z}_{\mathrm{a}}=\mathrm{Z}_{0} \sqrt{\mathrm{K}\left(1+\mathrm{K}^{2}\right)}$

$\mathrm{Z}_{\mathrm{a}}=\sqrt{2} \mathrm{Z}_{0}$ 


$$
\begin{aligned}
& Z_{b}=Z_{0} \sqrt{\left(\frac{1+K^{2}}{K^{2}}\right)} \\
& Z_{b}=\sqrt{2} Z_{0}
\end{aligned}
$$

$$
\mathrm{R}=2 \mathrm{Z}_{0}
$$

The general circuit of $\mathrm{N}$-section is shown in Fig. 2 which consists of a pair of equal length transmission line with isolation resistors from port 1 to 2 and 3 . The impedance bandwidth can be improved with increasing the sections. The impedance and isolation resistors values are considered to operate in the frequency range of 6-18 GHz [4].

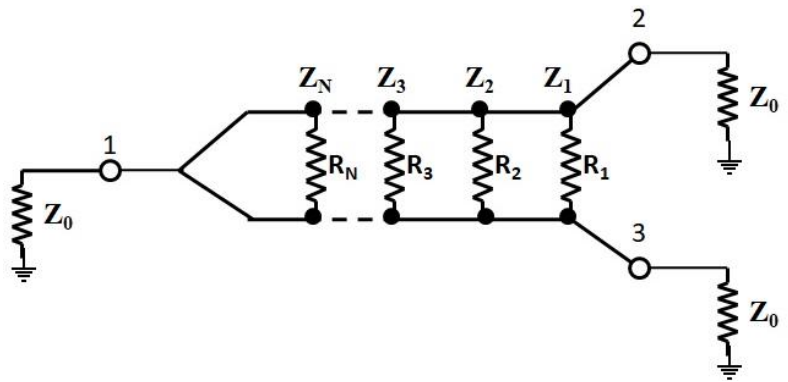

Fig. 2: General Circuit for Multiple-Section Three Ports WPD $\stackrel{\overline{\bar{F}}}{4}]$

Table 1: Impedance and Isolation Resistor Values [4]

\begin{tabular}{ll}
\hline $\begin{array}{l}\text { Quarter wave section impedance } \\
\text { (values in ohm) }\end{array}$ & Isolation resistance (values in ohm) \\
\hline $\mathrm{Z}_{1}=57.485$ & $\mathrm{R}_{1}=400$ \\
$\mathrm{Z}_{2}=70.7$ & $\mathrm{R}_{2}=107.8 \approx 100$ \\
$\mathrm{Z}_{3}=86.98 \approx 87$ & $\mathrm{R}_{3}=107.8 \approx 100$ \\
\hline
\end{tabular}

\section{Proposed design with simulated results and discussion}

The proposed WPD printed on a Rogers RT 5880 substrate with dielectric 2.2 and tangent loss 0.004 . The proposed design consists of 3-stages to increase the bandwidth. Each stage is designed with multi section 2- way WPD shown in Fig 3. Block diagram.

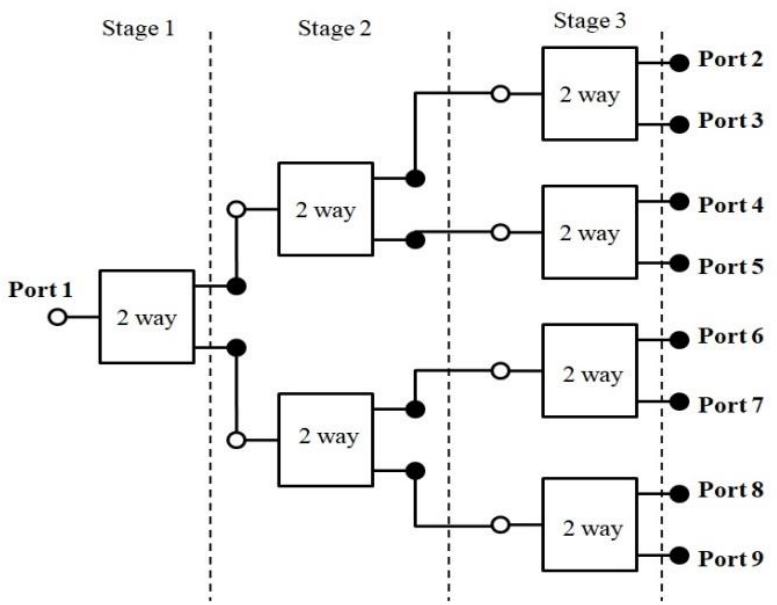

Fig. 3: Multi-Stage WPD Block Diagram.

The 2-Way WPD has designed with pair of equal length impedance values of $\mathrm{Z} 1, \mathrm{Z} 2$ and $\mathrm{Z} 3$ and isolation resistors (R1, R2 and R3) as shown in Table 1. By using ADS MLIN calculator we find the width and length of the microstrip lines with related impedance values shown in Table 1.The designed schematic diagram and layout diagram of two ways WPD in ADS software are shown in fig 4 and 5 respectively.

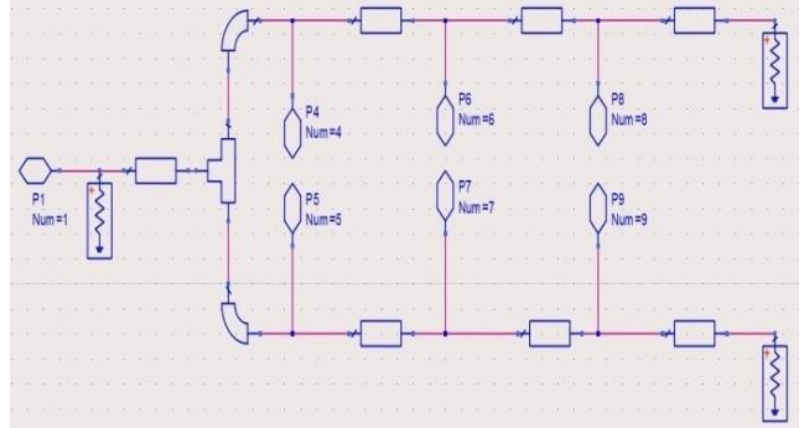

Fig. 4: Schematic Diagram of Single Multi-Section 2-Way WPD.

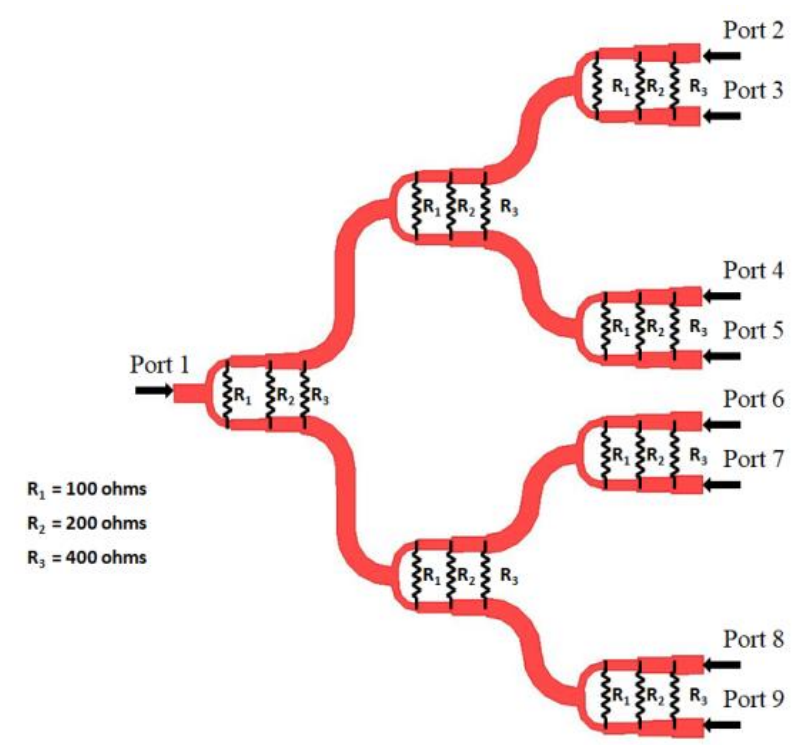

Fig. 5: Layout Diagram of Multi-Section 8-Way WPD.

The simulated results such as return loss, isolation and insertion loss are discussed in this section. The return loss S11 is below $10 \mathrm{~dB}$ from 6-18 GHz. The return loss of 8-way is given in Figure 6 while the isolation is presented in Figure 7. The insertion loss and phase are given in Figure 8 and 9 respectively. From the figures, it is observed that the impedance is matched at all ports so the network is lossless.

An isolation about $-15 \mathrm{~dB}$ is obtained throughout the frequency range of $6 \mathrm{GHz}$ to $18 \mathrm{GHz}$ and insertion loss about $-10.5 \mathrm{~dB}$ is observed at operating frequency and phase of all the ports is within \pm 3 degrees and an equal phase and equal amplitude is observed across all the output ports.

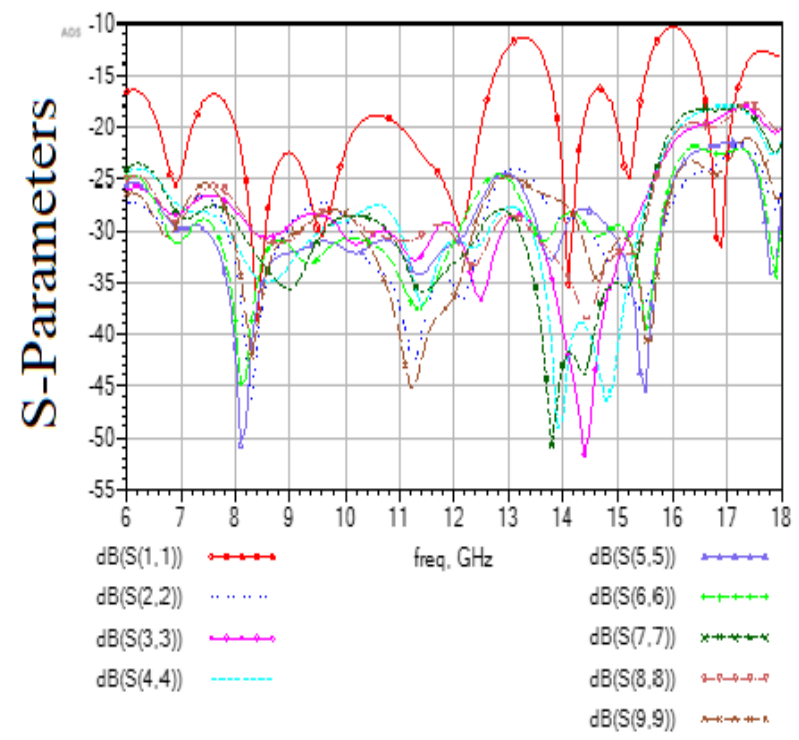

Fig. 6: Return Loss of Multi-Section 8-Way WPD. 


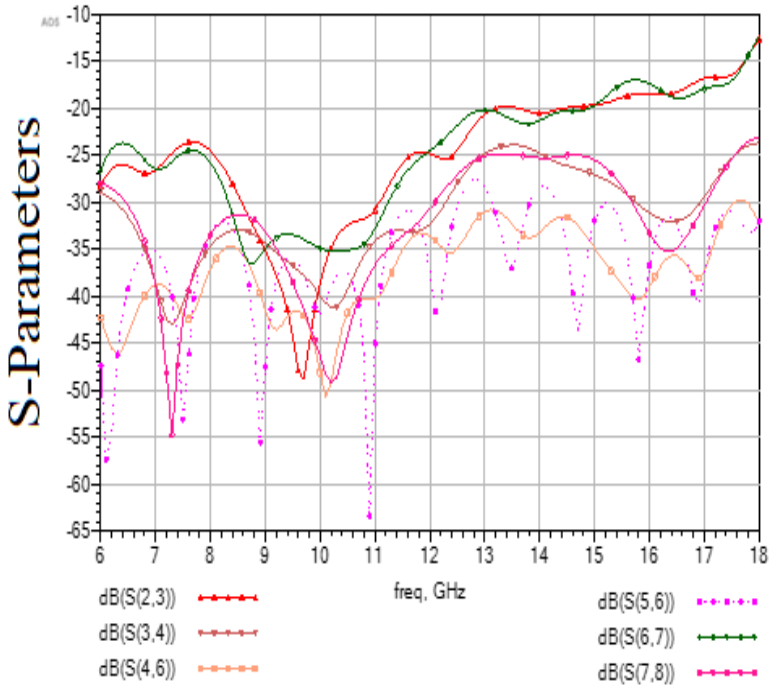

Fig. 7: Isolation of Multi-Section 8-Way WPD.

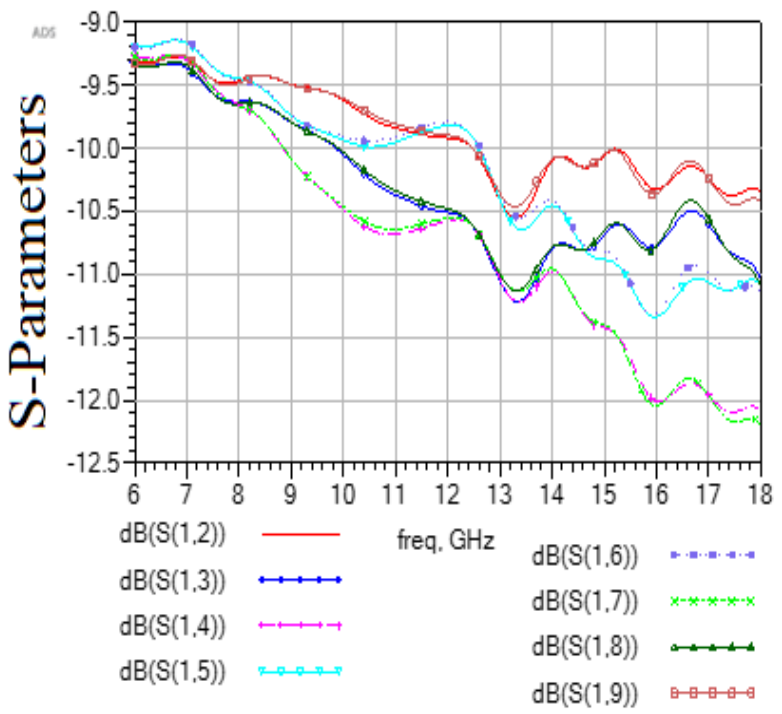

Fig. 8: Insertion Loss of Multi-Section 8-Way WPD.

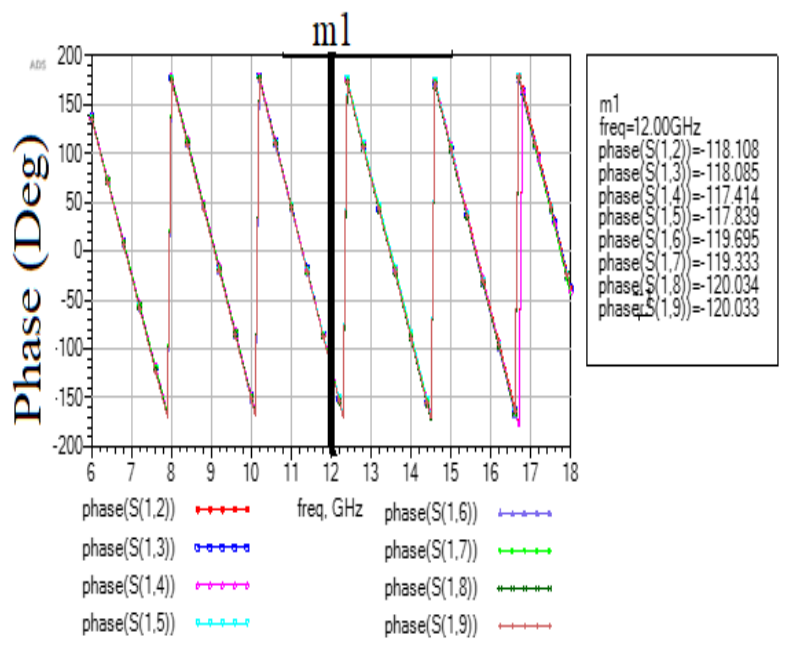

Fig. 9: Phase of Multi-Section 8-Way WPD.

\section{Conclusion}

The wideband multistage eight way WPD is designed and its results are discussed. By utilizing the multi-sections concept, a remarkably increase in the bandwidth is observed. It shows that proposed design is operating from $6-18 \mathrm{GHz}$ band with good iso- lation and insertion loss. Hence, the proposed power divider can be used for communication systems and defence applications.

\section{References}

[1] E. J. Wilkinson, "An N-Way Hybrid Power Divider," in IRE Transactions on Microwave Theory and Techniques, vol. 8, no. 1, pp. 116-118, January https://doi.org/10.1109/TMTT.1960.1124668.

[2] D. Antsos, R. Crist and L. Sukamto, "A novel Wilkinson power divider with predictable performance at K and Ka-band," 1994 IEEE MTT-S International Microwave Symposium Digest (Cat. No.94CH3389-4), San Diego, CA, USA, 1994, pp. 907-910 vol.2. https://doi.org/10.1109/MWSYM.1994.335210.

[3] P. H. Deng and Y. T. Chen, "New Wilkinson Power Dividers and Their Integration Applications to Four-Way and Filtering Dividers," in IEEE Transactions on Components, Packaging and Manufacturing Technology, vol. 4, no. 11, pp. 1828-1837, Nov. 2014 https://doi.org/10.1109/TCPMT.2014.2348571.

[4] S. B. Cohn, "A Class of Broadband Three-Port TEM-Mode Hybrids," in IEEE Transactions on Microwave Theory and Techniques, vol. 16, no. 2, pp. 110-116, February 1968. https://doi.org/10.1109/TMTT.1968.1126617.

[5] M. Chongcheawchamnan, S. Patisang, M. Krairiksh and I. D. Robertson, "Tri-Band Wilkinson Power Divider Using a Three-Section Transmission-Line Transformer," in IEEE Microwave and Wireless Components Letters, vol. 16, no. 8, pp. 452-454, Aug. 2006. https://doi.org/10.1109/LMWC.2006.879488.

[6] P. V. Naidu, V. Ravi and A. Kumar, "A novel compact unequal wideband Wilkinson power divider for UWB and EW applications," 2017 Progress in Electromagnetics Research Symposium Fall (PIERS - FALL), Singapore, 2017, pp. 737-742. https://doi.org/10.1109/PIERS-FALL.2017.8293232.

[7] Kumar, R., Naidu, P. V., \&Kamble, V. "Design of Asymmetric Slot Antenna with Meandered Narrow Rectangular Slit for Dual Band Applications". Progress in Electromagnetics Research B, (2014), 60, 111-123. https://doi.org/10.2528/PIERB14042205.

[8] Naidu, P. V., Kumar, A., \& Kumar, V. "A miniaturized triple band ACS-fed monopole printed antenna with meandered and circular ring shape resonators for WLAN/WiMAX applications".2017 Progress in Electromagnetics Research Symposium Fall (PIERS FALL), pp. 1933-1937. https://doi.org/10.1109/PIERSFALL.2017.8293454.

[9] Naidu, P. V., Kumar, A., \& Kumar, V. "A very small wideband asymmetric coplanar strip fed printed dual band antenna for advanced communication applications".2017 Progress in Electromagnetics Research Symposium Fall (PIERS - FALL), pp. 1928-1932. https://doi.org/10.1109/PIERS-FALL.2017.8293453.

[10] Naidu, P. V., \& Kumar, A. "ACS-fed multiband antenna loaded with staircase radiating strips for wireless communication systems".2017 Progress in Electromagnetics Research Symposium Fall (PIERS - FALL), pp. 26-30. https://doi.org/10.1109/PIERSFALL.2017.8293105.

[11] Naidu, P. V., Kumar, A., \& Kumar, V. (2017). "Simulation of meandered uniplanar printed antenna for multiband applications".2017 Progress in Electromagnetics Research Symposium - fall (PIERS FALL), pp. 1938-1941. https://doi.org/10.1109/PIERSFALL.2017.8293455.

[12] Kumar, A., Naidu, P. V., \& Kumar, V. (2017). "A novel rhombus shaped ACS fed multi band antenna loaded with meander branches for advanced communication applications" 2017 Progress in Electromagnetics Research Symposium - fall (PIERS - FALL), pp. 724730. https://doi.org/10.1109/PIERS-FALL.2017.8293230.

[13] Kumar, A., \& Naidu, P. V. (2016) "A compact O-shaped printed ACS fed monopole dual-band antenna for $2.4 \mathrm{GHz}$ Bluetooth and 5GHz WLAN/WiMAX applications". 2016 Progress in Electromagnetic Research Symposium (PIERS), pp. 2004-2008. https://doi.org/10.1109/PIERS.2016.7734856.

[14] Kumar, A., \& Naidu, P. V. (2016). "A novel compact printed ACS fed dual-band antenna for Bluetooth/WLAN/WiMAX applications". 2016 Progress in Electromagnetic Research Symposium (PIERS), pp. 2000-2003. https://doi.org/10.1109/PIERS.2016.7734855.

[15] Naidu, P. V., \&Malhotra, A. "A small ACS-fed tri-band antenna employing $\mathrm{C}$ and $\mathrm{L}$ shaped radiating branches for LTE/WLAN/WiMAX/ITU wireless communication applications. Analog Integrated Circuits and Signal Processing, (2015), 85(3), 489-496. https://doi.org/10.1007/s10470-015-0637-5.

[16] Naidu, P. V., \& Kumar, R. "A very small asymmetric coplanar strip fed multi-band antenna for wireless communication applications". 
Microsystem Technologies, (2015), 22(9), 2193-2200. https://doi.org/10.1007/s00542-015-2613-5.

[17] Naidu, P. V., Malhotra, A., \& Kumar, R. "A compact ACS-fed dual-band monopole antenna for LTE, WLAN/WiMAX and public safety applications". Microsystem Technologies, (2015), 22(5), 1021-1028. Doi: 10.1007/s00542-015-2562-z. https://doi.org/10.1007/s00542-015-2562-Z.

[18] Kumar, R., Naidu V, P., \&Kamble, V. "A compact asymmetric slot dual band antenna fed by CPW for PCS and UWB applications". International Journal of RF and Microwave Computer-Aided Engineering, (2014), 25(3), 243-254. doi:10.1002/mmce.20855. https://doi.org/10.1002/mmce.20855.

[19] Vummadisetty, P. N., \& Kumar, R. (2016). "Design of compact octagonal slotted hexagonal and rectangular shaped monopole antennas for dual/UWB applications". Turkish Journal of Electrical Engineering \& Computer Sciences, 24, 2806-2824. https://doi.org/10.3906/elk-1404-174.

[20] Naidu, V. P., \& Kumar, R. (2014). Design of Compact DualBand/Tri-Band CPW-Fed Monopole Antennas for WLAN/WiMAX Applications. Wireless Personal Communications, 82(1), 267-282. https://doi.org/10.1007/s11277-014-2207-z.

[21] Naidu, P. V., \& Kumar, R. "Design of Cpw-Fed Dual-Band Printed Monopole Antennas for Lte/Wimax/Wlan and Uwb Applications". Progress in Electromagnetics Research C, (2014), 54, 103-116. https://doi.org/10.2528/PIERC14071006.

[22] Colin, J-M. "Phased array radars in France: Present and future." Phased Array Systems and Technology, 1996, IEEE International Symposium on. IEEE, 1996 https://doi.org/10.1109/PAST.1996.566137.

[23] Rauf, Ali Ahmed, et al. "16 ways X-band wilkinson power divider for phased array transmitter." Applied Sciences and Technology (IBCAST), 2018 15th International Bhurban Conference on. IEEE, 2018. https://doi.org/10.1109/IBCAST.2018.8312321.

[24] Chou, Hsi-Tseng, and Hao-Ju Huang. "Multilevel Subarray Modularization to Construct Hierarchical Beamforming Networks for Phased Array of Antennas with Low Complexity." IEEE Transactions on Antennas and Propagation 65.11 (2017): 5819-5828. https://doi.org/10.1109/TAP.2017.2751657.

[25] Ibrahim, Mohamed I., et al. "Design and Performance Analysis of a Miniature, Dual-Frequency, Millimeter Wave Linear Phased Array Antenna." IEEE Transactions on Antennas and Propagation 65.12 (2017): 7029-7037. https://doi.org/10.1109/TAP.2017.2765542.

[26] Naidu, P. V. "Printed V-shape ACS-fed compact dual band antenna for bluetooth, LTE and WLAN/WiMAX applications". Microsystem Technologies, Vol. 23, N0.4, (2017), pp.1005-1015 https://doi.org/10.1007/s00542-016-2939-7

[27] Naidu, P. V., \& Kumar, A. "A novel ACS fed multi band antenna loaded with mirrored S and L shaped strips for advanced portable wireless communication applications". Microsystem Technologies, Vol. 23, No.10, (2017), pp. 4775-4783. https://doi.org/10.1007/s00542-017-3313-0.

[28] Naidu, P. V., \& Malhotra, A. "Design \& analysis of miniaturized asymmetric coplanar strip fed antenna for multi-band WLAN/WiMAX applications". Progress in Electromagnetics Research, Vol. 57, (2015), pp. 159-171 https://doi.org/10.2528/PIERC15042302.

[29] Naidu, P. V., \& Kumar, R. "Design of a compact ACS-fed dual band antenna for Bluetooth/WLAN and WiMAX applications". Progress in Electromagnetics Research, Vol. 55, (2014), pp. 63-72. https://doi.org/10.2528/PIERC14101803.

[30] Naidu, P. V. "Design, simulation of a compact triangular shaped dual-band Microstrip antenna for $2.4 \mathrm{GHz}$ bluetooth/WLAN and UWB Applications". Wireless Personal Communications, Vol. 95, No.2, (2017), pp.783-794. https://doi.org/10.1007/s11277-0163798-3.

[31] Kumar, R., Naidu, V. P., Kamble, V., \& Krishna, R. R. "Simulation, design of compact multi-band microstrip slot antennas for WiMAX/WLAN and UWB applications". Wireless Personal Communications, Vol. 80, No.3, (2015), pp. 1175-1192. https://doi.org/10.1007/s11277-014-2079-2.

[32] Naidu, P. V., \& Kumar, R. "A Compact Dual-Band Octagonal Slotted Printed Monopole Antenna for WLAN/ WiMAX and UWB Applications". Journal of Microwaves, Optoelectronics and Electromagnetic Applications, (2015), 14(1), 1-13. https://doi.org/10.1590/2179-10742015v14i1422.

[33] Vummadisetty, P. N., \& Kumar, A. "Compact Uniplanar Multi Feed Multi Band ACS Monopole Antenna Loaded With Multiple Radiating Branches for Portable Wireless Devices". Advanced

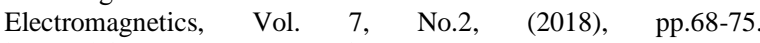
https://doi.org/10.7716/aem.v7i2.661
[34] Naidu, P. V., \& Kumar, A. "ACS-fed e-shaped dual band uniplanar printed antenna for modern wireless communication applications". Radioelectronics and Communications Systems, Vol. 61, (2018), pp. 87-93. https://doi.org/10.3103/S0735272718030019.

[35] Naidu, P. V., Kumar, A., \& Kumar, V. "Uniplanar Y and L shaped ACS fed multiband and wideband compact printed antenna for advanced wireless communication systems". Microsystem Technologies, Vol. 24, No.4, (2018), pp.2051-2061 https://doi.org/10.1007/s00542-017-3606-3.

[36] Vummadisetty, P. N., \& Kumar, A. "Multi feed multi band uniplanar ACS fed antenna with $\mathrm{N}$ shape and inverted $\mathrm{L}$ shape radiating branches for wireless applications". Microsystem Technologies, Vol. 24, No.4, (2018), pp.1863-1873. https://doi.org/10.1007/s00542-017-3565-8.

[37] Kumar, A., Naidu, P. V., \& Kumar, V. "A compact uniplanar ACS fed multi band low cost printed antenna for modern $2.4 / 3.5 / 5 \mathrm{GHz}$ applications". Microsystem Technologies, Vol. 24, No.3, (2018), pp 1413-1422. https://doi.org/10.1007/s00542-017-3556-9.

[38] Naidu, P. V., Kumar, A., \& Rajkumar, R. "Design, analysis and fabrication of compact dual band uniplanar meandered ACS fed antenna for $2.5 / 5 \mathrm{GHz}$ applications". Microsystem Technologies, pp.1-8. (2018). https://doi.org/10.1007/s00542-018-3937-8.

[39] Kumar, A., Naidu, P. V., Kumar, V., \& Ramasamy, A. K. "Design \& Development of compact uniplanar semi-hexagonal ACS fed multi-band antenna for portable system application". Progress in Electromagnetics Research, Vol. 60, (2017), pp.157-167. https://doi.org/10.2528/PIERM17080302.

[40] Naidu, P. V., \& Kumar, A. "Design and development of triple band ACS fed antenna with $\mathrm{M}$ and rectangular shaped radiating branches for $2.45 / 5 \mathrm{GHz}$ wireless applications". Microsystem Technologies, Vol. 23, No.12, (2017), pp.5841-5848 https://doi.org/10.1007/s00542-017-3430-9. 